\title{
Properties of Different Chemically Treated Woven Hemp Fabric Reinforced Bio-Composites
}

\author{
Arunjunai Raj Mahendran*, Günter Wuzella, Stefan Pichler and Herfried Lammer \\ Wood K Plus-Competence Center for Wood Composites and Wood Chemistry, Linz, A-4040, Austria \\ ${ }^{*}$ Corresponding Author: Arunjunai Raj Mahendran. Email: a.mahendran@wood-kplus.at
}

Received: 10 June 2021 Accepted: 04 November 2021

\begin{abstract}
The objective of this work is to carry out the chemical treatment for the hemp fabrics in a closed vacuum system and to prepare bio-based composites using treated hemp fabrics. The change in surface tension of the treated fabrics was measured using contact angle measurement and the wetting behavior using a tensiometer. Bio-based composites were fabricated using bio-based epoxy resin and different chemically treated fabrics. The flexural strength and dynamic water absorption behavior of the composites were characterized. The acetylated fabrics showed very good wetting behavior, and the contact angle values were marginally low compared to other treatment techniques. The bio-based composites fabricated using maleic anhydride treated fabrics achieved the flexural strength of $148 \mathrm{MPa}$ and the dynamic water absorption values were less than $6 \%$. The acetylated and maleic anhydride treatment methods were effective chemical treatments for the hemp fabrics and they enhanced both the wettability and fiber-matrix interaction. The chemical treatment methods that are carried out in the sealed environment can be utilized for all other natural fabrics that help overcome the moisture absorption behavior.
\end{abstract}

\section{KEYWORDS}

Bio-based composites; natural fiber; chemical treatment; mechanical properties

\section{Introduction}

Natural fibers are currently used as reinforcement in automotive [1,2] and structural composite parts due to their availability, lightweight, renewability, intrinsic specific properties and low abrasive nature. The natural fiber-reinforced bio-composites are prepared either using thermoplastic or thermoset matrix resins [3], and irrespective of matrix systems, fiber reinforcement has to be strong enough to transfer the structural stiffness to the composites through proper interfacial adhesion. The poor wetting behavior of the fiber may affect the interfacial adhesion, and especially hydrophilic nature of the natural fibers can cause poor compatibility with the hydrophobic polymer matrix. Recently, Célino et al. [4] published a review article on the hygroscopic behavior of plant fibers, the mechanism of moisture absorption and the influence of water on the final properties of natural fiber-reinforced composites.

In order to improve the interfacial compatibility, surface treatment or other modification is a must for the natural fiber reinforcement. During surface treatment, hydroxyl groups were converted into some other functional group or else new moieties were added to the end group for better chemical bonding. In some cases, the surface becomes rough for mechanical interlocking. In the literature, several studies on 
chemical and physical surface treatments of various natural fibers were reported, and they show that surface treatment not only improves the compatibility but also enhances the mechanical, thermal and other properties of the natural fiber-reinforced composites [5].

To modify the surface of the natural fiber, until now many treatment methods were already tested, and they were classified into three major groups: physical, chemical and biological treatments. The first one is a physical technique in which the surfaces of the fibers were modified using the methods like plasma, dielectric-barrier discharge, and corona. The physical pretreatment causes surface etching, and it could significantly increase the surface roughness. The etched surfaces significantly improve the interfacial adhesion between the matrix resin and fiber. Apart from that, they can also introduce some functional group on the surface of the natural fiber to improve interfacial adhesion. The physical treatment methods are high in investment costs, and even some of the methods are not suitable for 3D and complex parts.

The second one is a biological treatment, and it is carried out using enzymes or some biological processes. The enzyme removes the pectin without significant degradation of cellulose, and due to this process, composites reinforced with enzyme-treated fibers show higher toughness than other pretreated fibers. However, the higher cost associated with enzymes and equipment has limited this technology to pilot scale only. The fungi can also be used for pretreatment that is a highly efficient and environmentally friendly alternative method for the natural fiber surface treatment [6].

The third one is a chemical treatment, and in this technique various chemicals are used to activate the hydroxyl group and some new reactive moieties will be formed on the surface. The chemical treatment of natural fibers for composite applications is not quite new, and several authors as review or original research article [5,7-14] have already reported it. The methods that are used for chemical treatment are alkali, isocyanate, acrylation, permanganate treatment, acetylation, silane treatment, maleic anhydride and peroxide treatment. The above methods are used due to their relative simplicity, low cost and efficiency. The alkali treatment is carried out using aqueous sodium hydroxide, and it removes a certain amount of lignin, wax and oils on the surface of the fiber. The alkali treatment also depolymerizes the cellulose and bares the short length crystallites on the fibers [15]. The mechanical properties of the composites were increased under mild alkali treatment, but excess delignification of the natural fiber was observed at high alkali concentration. The above phenomenon results in damaging fiber and decreasing mechanical strength. Another popular grafting method for surface modification is the maleic anhydride treatment, and in this method, the natural fibers were esterified with maleic anhydride. Acetylation is also one among the surface treatment methods, and in this process, the hydroxyl group of the cell wall is replaced by the acetyl functional groups. The hygroscopic property of the natural fibers are reduced, and the fiber matrix adhesion is improved. Rong et al. [16] investigated the effect of acetylation treatment on the mechanical properties of the sisal fiber reinforced. Similarly, Hill et al. [17] investigated the potential of acetylation to improve the properties of coir, oil palm fiber, flax and jute fiber reinforced composites. Bledzki et al. [18] investigated the effect of acetylation on the properties of the flax fiber/polypropylene composites. Sreekala et al. [19] investigated Futhermore the effect of acetylation on the water-sorption behavior. The results of all the above investigations show that acetylated fibers improve the mechanical strength of the reinforced composites, and at the same time, hydrophilicity and water uptake of the fibers were decreased, respectively. Non-ionic surfactants, which present a hydrophilic head and hydrophobic tail, can also be used for the surface treatment of the fibers. Non-ionic surfactants are most widely used for surface cleaning and have no charge in aqueous solution. Joshy et al. [20] made surface modification for isora fiber using non-ionic surfactant triton and studied the influence of fiber surface modification on the mechanical performance of Isora-Polyester composites. The chemical modification of fiber improved fiber/matrix interaction as evidenced by the enhanced tensile and flexural properties. The above four modification methods used for chemical surface treatment were effective, but they are mostly carried out 
for the loose fibers or individual yarn. If the chemical treatments can be carried out for the woven fabrics, then there is a chance of shrinkage.

In this investigation, a novel effort had been made to carry out the complete chemical treatment in a sealed environment, and for this purpose, the fiber treatment was carried out in a closed vacuum bag process. The above fiber treatment methods offered an easy and safe handling of chemicals (ecological benefit).

In this investigation, the woven hemp fabrics were treated using sodium hydroxide (alkaline), maleic anhydride, acetylation and triton treatment methods. After surface modification, wetting of a solid by a test liquid was characterized using contact angle measurement and the wetting behavior using tensiometer. The treated woven fabrics were used as reinforcement for the bio-based composite. The flexural strengths and water absorption behavior of the fiber-reinforced composites were characterized.

\section{Materials and Methods}

Two different hemp fabrics (FW-Klara and FW-Arctic) were purchased from Cavvas Limited, Romania. The areal weights of FW-Klara and FW-Arctic fabrics were $178 \mathrm{gsm}$ (gram per square meter) (Weave 1) and 416 gsm (Weave 2), respectively. Weave 1 has 62.5 tex yarn both in warp and weft direction (balanced), Weave 2 has 400 tex in warp and 200 tex in weft direction. The bio-based matrix resin Super Sap ${ }^{\circledR}$ was purchased from Entropy Resin, Spain. The epoxy resin Super Sap CLR was used along with the INF curing agent. The chemicals used for the fiber treatment are of laboratory reagent grade, and test fluid epoxidized hemp seed oil (EHSO) used for tensiometer measurement was synthesized in the laboratory.

The chemical treatment was carried out in a closed vacuum bag as shown in Fig. 1. The untreated fabrics were kept on a metal plate, and the spiral tubes were fixed on both sides of the fabrics. The whole setup was covered with the vacuum bag using sealant tape, and the valves (V1 and V2) were attached to the inlet and outlet tubes. The one end of the outlet tube was connected to the spiral tube, and another end of the outlet tube was connected to the solvent trap. The solvent trap was connected to the vacuum pump.

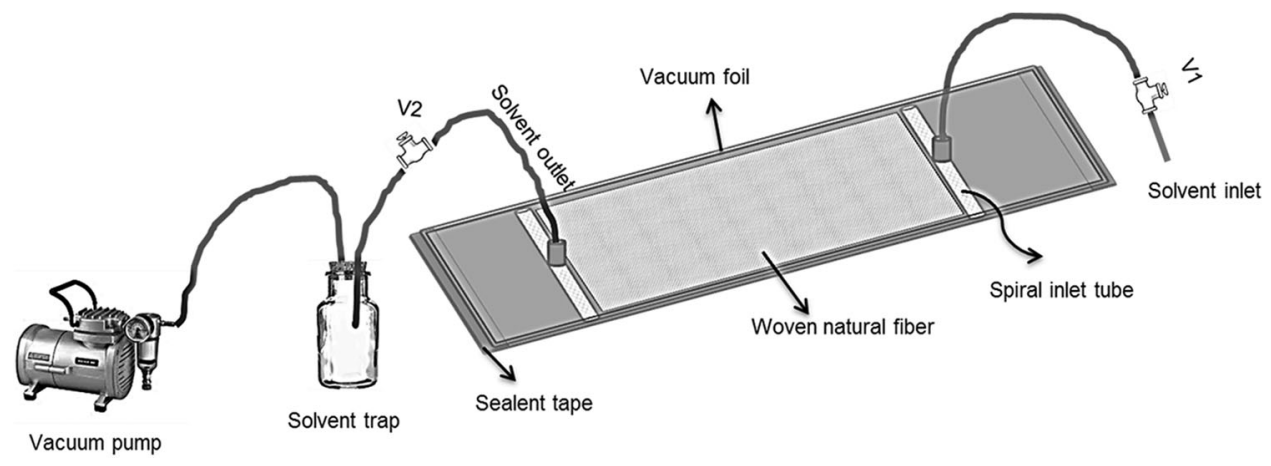

Figure 1: Schematic representation of chemical treatment method

Initially, valve V1 was closed, and a whole system was kept under vacuum ( -0.9 bar $)$, and the leak check was done before the start. During fiber treatment, the solution was introduced into the woven fabric through a flexible inlet hose, and it was distributed with the help of spiral inlet tube by opening the valve V1. Under the vacuum pressure, solution infuses through the reinforcement, and once the solution completely fills the mold, then the supply is cut off by closing the valve V1.

The fabrics were treated with the chemicals for an allowed duration of time based on the treatment method. Finally, valve V2 was opened to drain the solution from the vacuum bag. Once the solution was completely removed, then the fabrics were washed several times either with deionized water or with solvent. The washed fabrics were oven dried for the duration of $16 \mathrm{~h}$. 


\subsection{Chemical Treatment of the Woven Fabric}

\subsubsection{Alkali Treatment}

The woven fabrics were treated with $10 \%$ sodium hydroxide for the duration of $16 \mathrm{~h}$ in a closed vacuum infusion process shown in Fig. 1, and then washed with deionized water until the $\mathrm{pH}$ attains the neutral value. The treated fabrics were dried in an oven at $60^{\circ} \mathrm{C}$ for the duration of $16 \mathrm{~h}$.

\subsubsection{Acetylation}

The alkali treated fabrics were first reacted with glacial acetic acid for the duration of $2 \mathrm{~h}$, and then it was treated with acetic anhydride containing a small amount of sulphuric acid catalyst at the temperature of $60^{\circ} \mathrm{C}$ for the duration of $2 \mathrm{~h}$. The treated fabrics were washed with deionized water and then dried in an oven at $60^{\circ} \mathrm{C}$ for the duration of $16 \mathrm{~h}$.

\subsubsection{Maleic Anhydride Treatment}

The alkali treated fabrics were reacted with a solution having $6 \%$ maleic anhydride in ethyl acetate for the duration of $1 \mathrm{~h}$. The treated fabrics were washed with ethanol until they are free from maleic anhydride. The washed fabrics were dried in an oven at $60^{\circ} \mathrm{C}$ for the duration of $16 \mathrm{~h}$.

\subsubsection{Triton Treatment}

The alkali treated fabrics were reacted with a solution having 5\% Triton $\mathrm{x}-100$ in ethanol for the duration of $2 \mathrm{~h}$ and then washed with deionized water. The treated fabrics were dried in an oven at $60^{\circ} \mathrm{C}$ for the duration of $16 \mathrm{~h}$.

The wetting behavior of the treated fabrics was characterized using Data Physics DCAT 11 EC tensiometer and was measured using a special accessory holder for fiber bundles, fabrics and non-woven strands. The following test fluids were used: epoxidized hemp seed oil (EHSO) and EHSO with methyl tetra hydro phthalic anhydride curing agent. EHSO has been chosen because it contains a polar group, so it behaves slightly polar. The contact angle for the treated fabrics was measured using Data Physics OCA 35. For the measurement, five different spots were chosen, and then the results were averaged.

\subsection{Bio-Composites from Treated Fabrics}

The treated fabrics were impregnated with bio-based Super Sap ${ }^{\circledR}$ epoxy resin by using resin infusion technique. The resin was cured at room temperature for the duration of $16 \mathrm{~h}$. The three-point bending test (Flexural strength and modulus) was carried out for the bio-composites, and it was performed on a Frank 81565 testing machine (Zwick GmbH \& Co. KG, Ulm, Germany). The flexural tests were carried out as per the ISO 178:1993 norm, and the size of the specimens was $120 \mathrm{~mm} \times 15 \mathrm{~mm} \times 3 \mathrm{~mm}$. The samples were tested at room temperature, and a specific crosshead speed of $2 \mathrm{~mm} / \mathrm{min}$ was used. The fiber and pore volume fraction of the bio-composites was characterized using the formula already described in the literature [21].

$v_{f}=\frac{m_{f}}{\rho_{f}} \equiv \frac{n * m_{f}^{\prime} * A_{c}}{\rho_{f}}$

$v_{m}=\frac{m_{m}}{\rho_{m}}$

where $\mathrm{n}$ is the number of plies, $\mathrm{m}_{\mathrm{f}}$ is the areal weight of the plies, $\mathrm{A}_{\mathrm{c}}$ is the surface area of the rectangular composite and $\rho_{\mathrm{f}}$ and $\rho_{\mathrm{m}}$ are the densities of the fiber and matrix, respectively. The literature value was considered for the density of the fiber $\left(1.5 \mathrm{~g} \mathrm{~cm}^{-3}\right)$. The pore volume $v_{p}$ is calculated using the following formula: 
$v_{p}=\left(v_{c}-v_{f}\right)-\frac{m_{c}-m_{f}}{\rho_{m}}$

where $m_{c}$ is the weight of the composite.

From the calculated pore $\left(v_{p}\right)$ and fiber $\left(v_{f}\right)$ volumes, the volume fractions $(\varphi)$ of the pore, fiber and matrix were determined using the formula:

$\varphi_{p}=\frac{v_{p}}{v_{c}}=\frac{v_{p}}{A_{c} * t_{c}}$

$\varphi_{f}=\frac{v_{f}}{v_{c}}=\frac{v_{f}}{A_{c} * t_{c}}$

$\varphi_{m}=1-\varphi_{f}-\varphi_{p}$

where $t_{c}$ is the thickness of the composite.

For the water absorption and thickness swelling test, the specimens were immersed in deionized water for a period of time. The immersed samples were taken out, and the surface water was wiped off using blotting paper. The changes in weight and thickness were measured with respect to immersion time, and it was performed until a constant weight gain was achieved. The percentage of water absorption and thickness swelling of the specimens were determined using the following equations:

$W_{W A}=\frac{W_{e}-W_{0}}{W_{o}} * 100$

where $\mathrm{W}_{0}$ is the weight of the specimen before immersion, and $\mathrm{W}_{\mathrm{e}}$ is the weight of the specimen after a certain duration of time.

$T_{T S}=\frac{T_{e}-T_{0}}{T_{o}} * 100$

where $T_{0}$ is the thickness of the specimen before immersion, and $T_{e}$ is the weight of the specimen after a certain duration of time.

\section{Results and Discussions}

The wetting behavior of the untreated and treated hemp fabrics was measured using a tensiometer. The term "wetting" describes the degree to which test liquid spreads on the fabric and the other term "spreading" refers to the complete wetting of the fabric. The results for the Weaves 1 and 2 fabrics measured with test fluid EHSO and EHSO with anhydride are shown in Figs. 2a, 2b, 3a and 3b, respectively. An exponential increase in the weight gain was observed for all the fabrics in the initial $20 \mathrm{~s}$, and then it reached a plateau (saturation). For the Weave 1, maleic anhydride-treated fabrics have achieved the saturation level (test liquid EHSO/ anhydride) much faster than other fabrics, which means complete wetting of the fabric had occurred earlier than other fabrics. The untreated fabric took relatively more time than other surface-treated fabrics. The anhydride carbonyl groups have very good interaction with the EHSO/anhydride test liquid than other functional groups. In case of the Weave 2, not so much differences were observed with EHSO test liquid, but the EHSO/anhydride test fluid showed huge differences after initial $20 \mathrm{~s}$. The acetylated fabrics reached the saturation level within a short duration of time (test liquid EHSO) compared to other treated fabrics. A hydrophobic acetyl group $\left(\mathrm{CH}_{3} \mathrm{CO}\right)$ replaces the hydroxyl groups during acetylation, and due to that, they had perfect interaction with the EHSO test liquid. The result shows that chemical treatments have enhanced the wettability by introducing different functional groups. The spreading of the test liquid on the fabric was also much quicker due to increased wettability. 

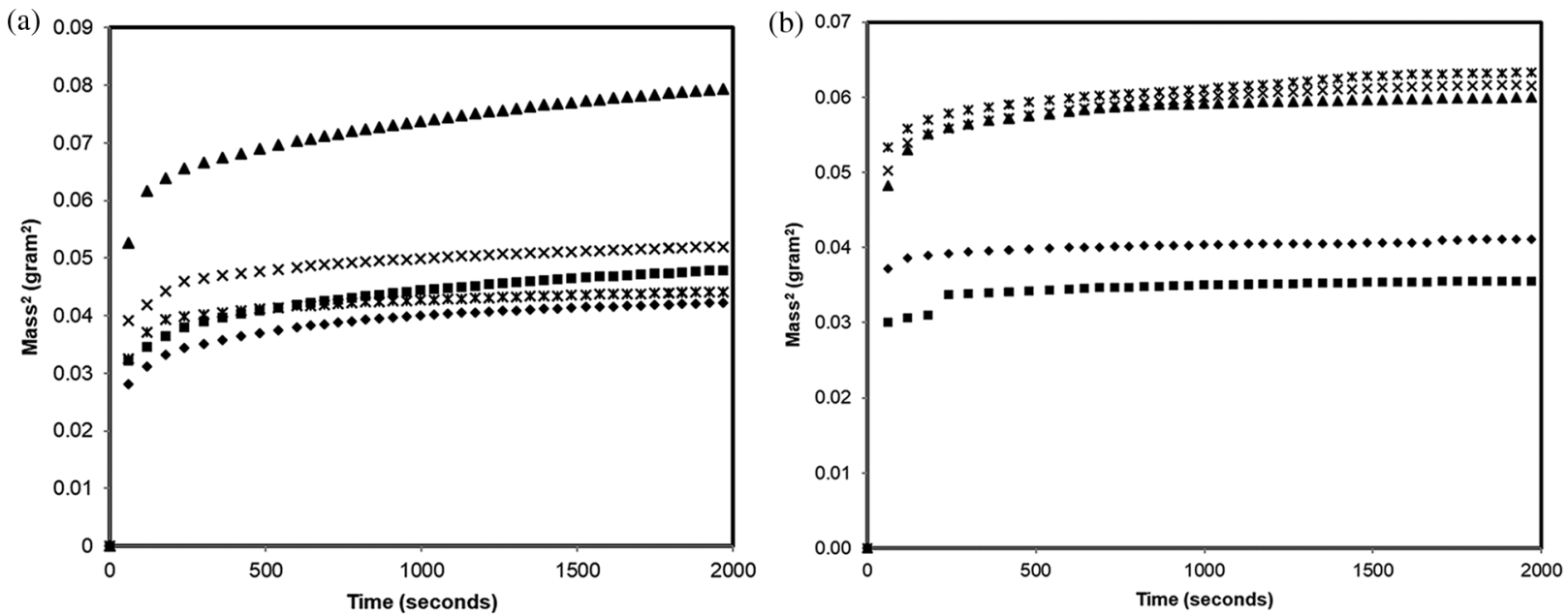

Figure 2: The increase in weight gain with respect to time for the Weave 1 fabric: (a) EHSO as test liquid (b) EHSO/anhydride as test liquid ( Acetylated; $\square$ Maleic anhydride; $\Delta$ Sodium hydroxide; $\times$ Triton; $*$ Untreated)
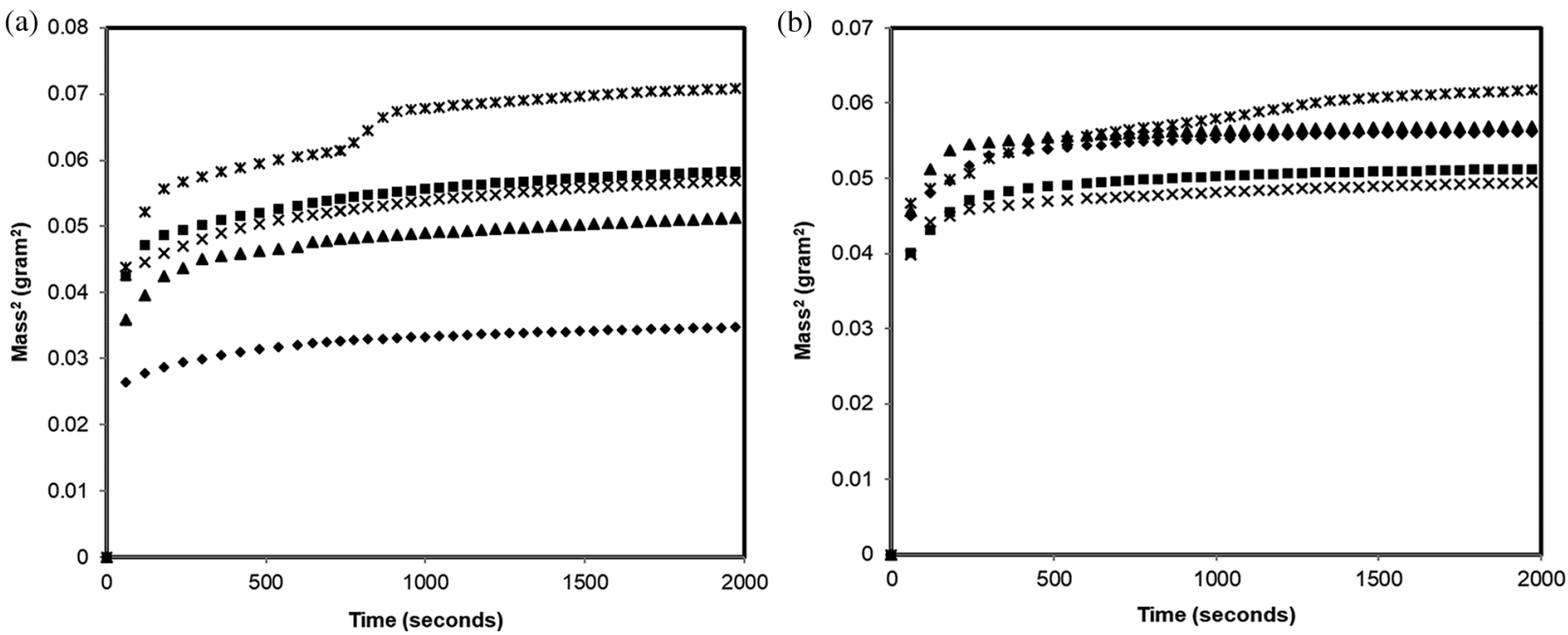

Figure 3: The increase in weight gain with respect to time for the Weave 2 fabric: (a) EHSO as test liquid (b) EHSO/anhydride as test liquid ( Acetylated; $\bullet$ Maleic anhydride; $\Delta$ Sodium hydroxide; $\times$ Triton; $*$ Untreated)

\subsection{Characterizing the Wetting Behavior of Treated Fabrics Using Contact Angle Values}

The contact angle for the treated fibers is used to measure the cleanliness, the effect of surface treatment, adhesiveness and water repellency. The Weave 1 fabrics have achieved lower contact angle values than the Weave 2 fabrics for all test liquids, which means the wetting behavior of the Weave 1 fabric is higher than the Weave 2 fabrics. The reason is that linear mass density of fiber yarns (tex) used in the Weave 1 fabric is comparatively less which eventually decreases the yarn surface area. The size of the pores between fibers in the yarn structure and the packing density is mostly determined by the yarn surface area. Hence, due to low yarn surface area, the Weave 1 fabric had a low-packing density and more pores between fibers. The above reasons are the cause for the lower contact angles. 
While comparing the contact angles of two test fluids, the fabrics tested with EHSO/anhydride test fluid had lower contact angle values than the EHSO test fluid due to the polarity (see Table 1). The polarity of the EHSO/anhydride is slightly higher than EHSO alone because of the very polar functional group in the anhydride structure. After surface treatment, polar end groups were formed on the surface of the fiber, and they reacted very well with the EHSO/anhydride test fluid than EHSO. Due to polar-polar interaction, the strength of adhesive force between the fibers, and the test liquid was increased. The vegetable oil is a non-polar liquid, but after epoxidation (EHSO), more polar groups were introduced into the triglyceride structure. The polar groups in the fatty acid chains have interacted with the polar group on the fiber surface, and the non-polar groups in the triglyceride chains were sticking away from the fiber surface. Due to the above reason, slightly higher contact angle values were achieved for EHSO compared to EHSO/anhydride mixture.

Table 1: Contact angle values and diameter of the drop for the untreated and treated fabrics

\begin{tabular}{|c|c|c|c|c|}
\hline & \multicolumn{2}{|c|}{ Contact angle values } & \multicolumn{2}{|c|}{ Diameter of the drop } \\
\hline & Mean $\left(^{\circ}\right)$ & Standard deviation $\left(^{\circ}\right)$ & Mean (mm) & Standard deviation $(\mathrm{mm})$ \\
\hline \multicolumn{5}{|l|}{ EHSO (Weave 1) } \\
\hline Untreated & 51.30 & 5.39 & 2.41 & 0.24 \\
\hline Sodium hydroxide & 41.37 & 2.95 & 2.93 & 0.27 \\
\hline Acetylated & 40.65 & 2.72 & 2.98 & 0.15 \\
\hline Maleic anhydride & 38.80 & 3.40 & 2.78 & 0.24 \\
\hline Triton & 42.13 & 3.71 & 2.82 & 0.28 \\
\hline \multicolumn{5}{|c|}{ EHSO/Anhydride (Weave 1) } \\
\hline Untreated & 46.48 & 2.81 & 3.06 & 0.09 \\
\hline Sodium hydroxide & 38.04 & 5.40 & 3.44 & 0.18 \\
\hline Acetylated & 33.82 & 9.89 & 3.61 & 0.33 \\
\hline Maleic anhydride & 31.43 & 1.08 & 3.71 & 0.09 \\
\hline Triton & 37.38 & 3.61 & 3.49 & 0.20 \\
\hline \multicolumn{5}{|l|}{ EHSO (Weave 2) } \\
\hline Untreated & 58.19 & 2.82 & 2.26 & 0.11 \\
\hline Sodium hydroxide & 57.92 & 2.60 & 2.64 & 0.26 \\
\hline Acetylated & 51.18 & 3.31 & 2.41 & 0.19 \\
\hline Maleic anhydride & 50.01 & 5.50 & 2.80 & 0.17 \\
\hline Triton & 53.32 & 3.81 & 2.62 & 0.09 \\
\hline \multicolumn{5}{|c|}{ EHSO/Anhydride (Weave 2) } \\
\hline Untreated & 56.78 & 4.33 & 3.12 & 0.16 \\
\hline Sodium hydroxide & 51.92 & 7.55 & 2.98 & 0.23 \\
\hline Acetylated & 50.23 & 1.17 & 3.00 & 0.09 \\
\hline Maleic anhydride & 49.15 & 6.07 & 3.04 & 0.24 \\
\hline Triton & 50.73 & 2.74 & 3.08 & 0.04 \\
\hline
\end{tabular}


The untreated fabrics showed the highest contact angle values compared to chemically treated fabrics because on the epidermis of the fiber cuticle layer the highest content of the wax is present, which reduces the adhesive force between fiber surface and test liquid. Among different chemical treatment methods, maleic anhydride treated fabrics have achieved the lowest contact angle value (for the Weave 1 fabric) and least value of $31^{\circ}$ was observed for the EHSO/anhydride test liquid. The contact angle values are in the following order although the differences were marginally low: maleic anhydride $<$ acetylated $<$ Triton-X-100 < Sodium hydroxide. For the Weave 2 fabrics, a pronounced change in contact angle values was observed only using EHSO test liquid. As mentioned before, the Weave 1 fabrics have achieved higher wetting behavior due to their yarn structure and the effective chemical treatment on the fiber surface.

\subsection{Mechanical Properties of the Bio-Based Composites}

The flexural strength results were normalized for a $25 \%$ fiber volume fraction, and the normalized flexural strength of composites for the Weave 1 fabrics is shown in Fig. 4. Among the three different treatment methods (maleic anhydride, triton and sodium hydroxide), maleic anhydride-treated fabrics have achieved the maximum flexural strength of $143 \mathrm{MPa}$. Only a marginal difference in flexural strengths was observed among treated fabrics. However, the flexural strengths of all treated fabrics are obviously higher than the untreated fabrics. A good bonding force between fiber and matrix will improve the mechanical strength, and in this case, an increase in flexural strength was observed for the treated fabrics that shows the improvement in fiber-matrix interaction. During chemical treatment, not only chemical modification occurs on the fiber surface but also the topography will be changed to a rough surface [22]. The rough structure can also help improve the fiber matrix interaction [23].

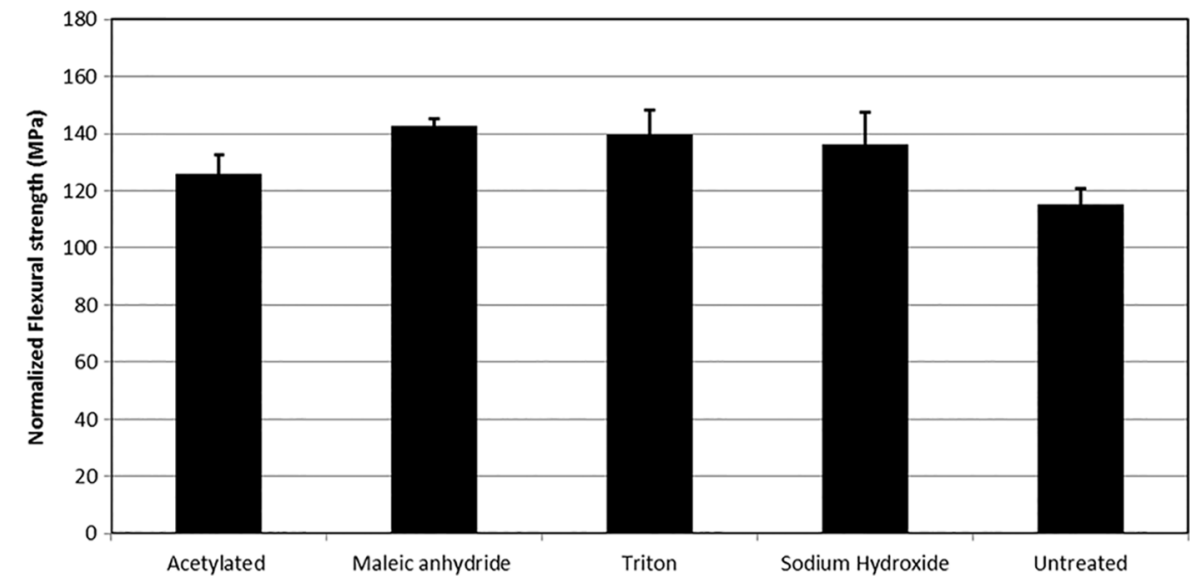

Figure 4: Normalized flexural strength for treated and untreated hemp fabrics in a bio-based matrix resin for the Weave 1 fabrics

The normalized flexural strength of the bio-based composites prepared using the Weave 2 fabrics is shown in Fig. 5. Overall, the surface treated fabrics had higher flexural strength than untreated fabrics, and especially acetylated fabric reinforced composites showed the highest flexural strength (148 MPa). Acetylation under specific temperature and condition is important or else it could result in structural damage and weaker mechanical properties. For example, Hill et al. [24] observed the above effect for the coir fibers. The coir fibers that were treated at $120^{\circ} \mathrm{C}$ lost their mechanical strength but at $100^{\circ} \mathrm{C}$ yielded improved mechanical performance [24]. In the current investigation, the treatment was carried out under a mild environment, which avoided the fiber damage and increased the fiber matrix interaction. 


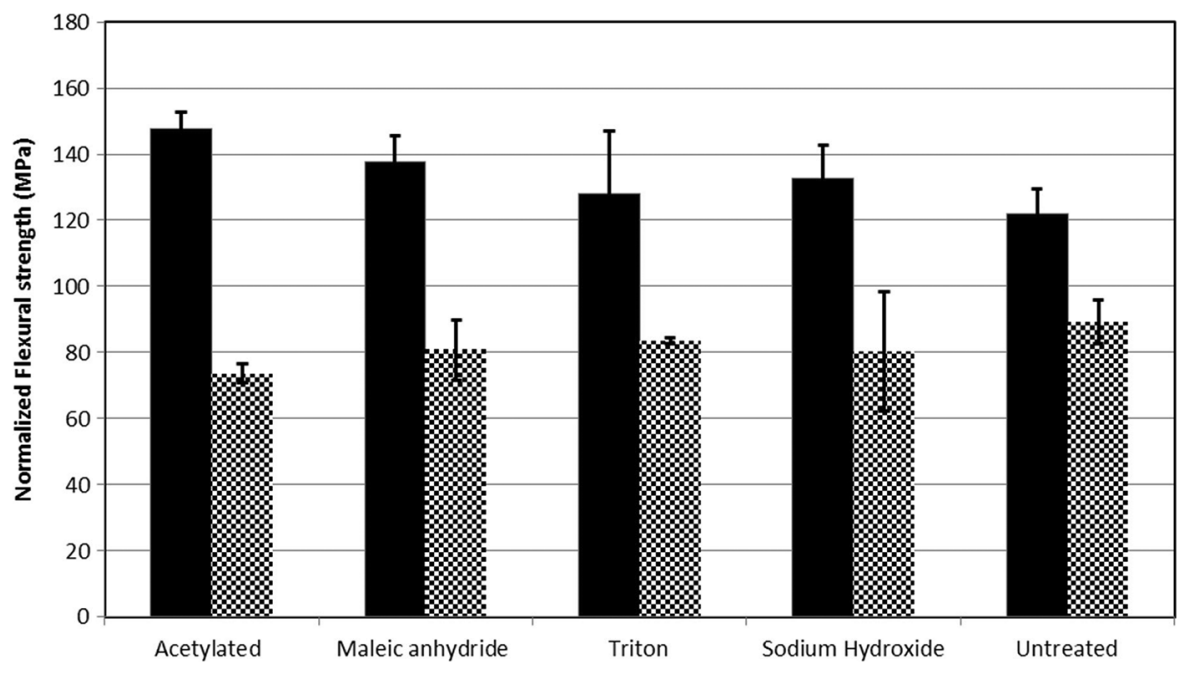

Figure 5: Normalized flexural strength for treated and untreated hemp fabrics in a bio-based matrix resin for the Weave 2 fabrics on warp (filled) and weft (checked) direction

The untreated fabrics have achieved the highest fiber volume fraction for both weave types, and this is due to the uniform yarn structure, which presumably increased the compaction behavior of the fabrics while processing. In case of treated fabrics, marginal shrinkage was observed which reduces the packing density of reinforcement and also its compaction behavior.

\subsection{Dynamic Water Absorption Behavior of the Reinforced Composites}

The dynamic water absorption behaviors of the composites were determined by measuring the weight gain and thickness swelling of the composites with respect to time. The composites with untreated fabrics showed highest water absorption. An exponential increase in water absorption behavior was observed up to 17 days for the Weave 1 fabrics (Fig. 6), and after that due to saturation, there was only marginal increase in water absorption. The maleic anhydride-treated fabrics had the lowest water uptake.

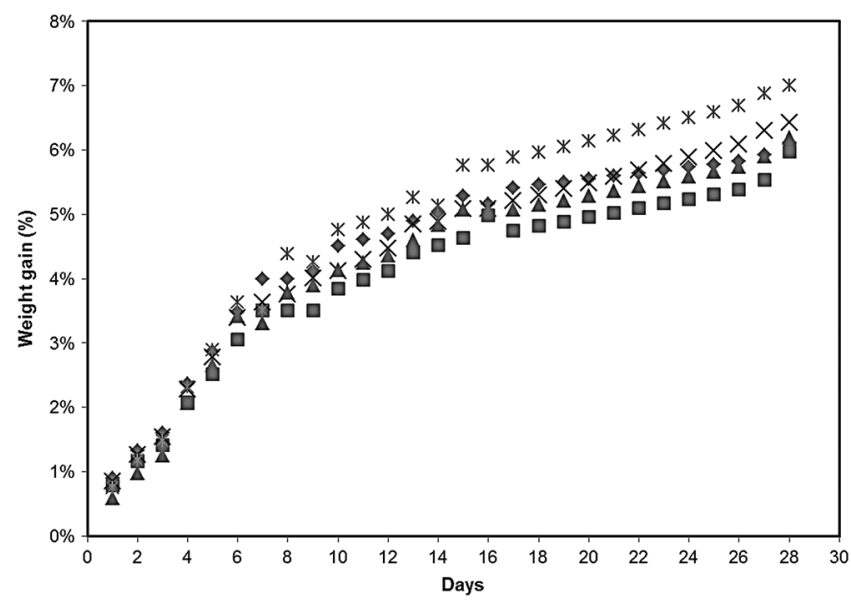

Figure 6: Water absorption behavior of the composites made using different chemically treated Weave 1 fabrics ( Acetylated; $\boldsymbol{\bullet}$ Maleic anhydride; $\times$ Sodium hydroxide; $\boldsymbol{\Delta}$ Triton; $*$ Untreated) 
Again, the similar trend was observed for the Weave 2 fabrics, but the exponential increase in water absorption value was observed up to 20 days (Fig. 7). The composites with acetylated fabrics had the least water absorption compared to other fabrics.

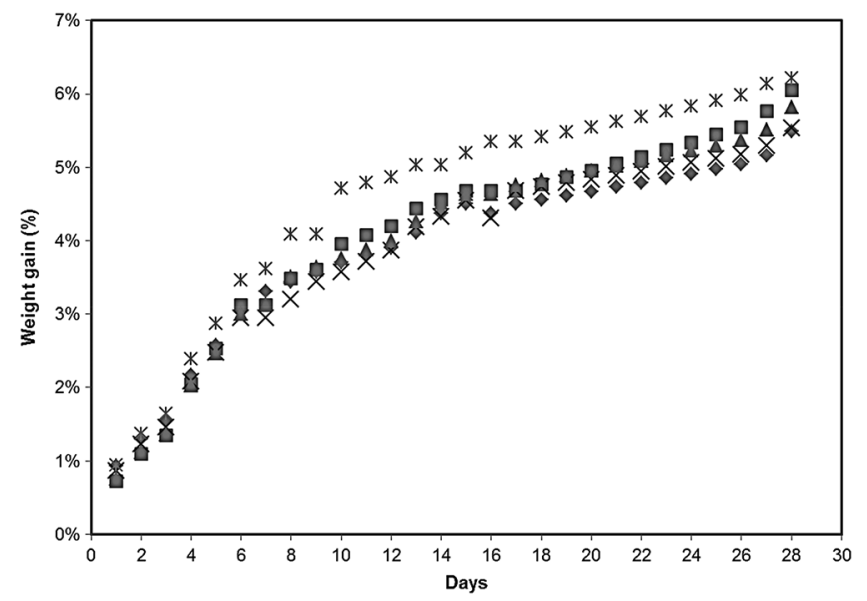

Figure 7: Water absorption behavior of the composites made using different chemically treated Weave 2 fabrics $($ Acetylated; $\square$ Maleic anhydride; $\times$ Sodium hydroxide; $\Delta$ Triton; $*$ Untreated)

The water absorption behavior of the composites depends not only on the fiber matrix interaction but also on the porosity, and it was calculated for all the composites (Tables 2 and 3). The Weave 1 fabric had much lower pore volume fraction than the Weave 2 fabrics due to their fiber structure and very good compaction behavior. The untreated fabric reinforced composite had porosity of up to 5\%. During immersion, the water molecule can penetrate through the pores and leads to increase in water absorption. As a whole, pore volume fraction and the amount of fiber loading have a huge influence on the dynamic water absorption behavior of the natural fiber-reinforced composites.

Table 2: Properties of hemp reinforced bio-composites fabricated using treated and untreated Weave 1 fabrics

\begin{tabular}{llllll}
\hline $\begin{array}{l}\text { Fabrics used for preparing } \\
\text { bio-composites }\end{array}$ & $\begin{array}{l}\text { Number } \\
\text { of plies }\end{array}$ & $\begin{array}{l}\text { Biocomposite } \\
\text { thickness t }[\mathrm{mm}]\end{array}$ & $\begin{array}{l}\text { Biocomposite } \\
\text { density } \rho\left[\mathrm{g} / \mathrm{cm}^{3}\right]\end{array}$ & $\begin{array}{l}\text { Fiber volume } \\
\text { fraction }(\%)\end{array}$ & $\begin{array}{l}\text { Pore volume } \\
\text { fraction }(\%)\end{array}$ \\
\hline Acetylated & 8 & 3.64 & 1.190 & 25.41 & 1.75 \\
Maleic anhydride & 8 & 3.61 & 1.218 & 23.87 & 1.36 \\
Triton & 8 & 3.45 & 1.198 & 25.04 & 1.59 \\
Sodium hydroxide & 8 & 3.39 & 1.226 & 24.56 & 2.05 \\
Untreated & 8 & 2.78 & 1.218 & 33.20 & 4.20 \\
\hline
\end{tabular}

Table 3: Properties of hemp reinforced bio-composites fabricated using treated and untreated Weave 2 fabrics

\begin{tabular}{llllll}
\hline $\begin{array}{l}\text { Fabrics used for preparing } \\
\text { bio-composites }\end{array}$ & $\begin{array}{l}\text { Number } \\
\text { of plies }\end{array}$ & $\begin{array}{l}\text { Biocomposite } \\
\text { thickness } \mathrm{t}[\mathrm{mm}]\end{array}$ & $\begin{array}{l}\text { Biocomposite } \\
\text { density } \rho\left[\mathrm{g} / \mathrm{cm}^{3}\right]\end{array}$ & $\begin{array}{l}\text { Fiber volume } \\
\text { fraction }(\%)\end{array}$ & $\begin{array}{l}\text { Pore volume } \\
\text { fraction }(\%)\end{array}$ \\
\hline Acetylated & 4 & 3.65 & 1.198 & 25.72 & 2.39 \\
Maleic anhydride & 4 & 4.16 & 1.201 & 22.53 & 3.69 \\
Triton & 4 & 4.03 & 1.198 & 23.29 & 2.93 \\
Sodium hydroxide & 4 & 3.80 & 1.201 & 24.67 & 3.04 \\
Untreated & 4 & 3.73 & 1.197 & 29.78 & 4.98 \\
\hline
\end{tabular}




\section{Conclusions}

The chemical treatment of yarns and fibers has been performed for a long time, but treating the woven fabrics in a closed vacuum bagging is quite new, and this article shows the feasibility of this novel treatment method. The fiber wetting behavior is strongly influenced by weave architecture, surface area and other factors like packing density and pore structures. The treated fabric showed an increase in mechanical performance, and they are highly resistant to water absorption behavior. The increase in flexural strength of the composites made using treated fabrics shows the strong increase in fiber-matrix interaction. The pore volume fraction has highly influenced the water absorption behavior. Overall, acetylated and maleic anhydride treated fabrics have achieved better properties and good wettability than other treatment methods. As a result, it is concluded that pretreatment is necessary for the natural fibers to improve not only the mechanical strength but also other properties like wetting, water resistance.

Acknowledgement: This research was supported by the Austrian Research Promotion Agency (FFG). We thank Thomas Sepperer for technical assistance and evaluating some results.

Funding Statement: The authors received no specific funding for this study.

Conflicts of Interest: The authors declare that they have no conflicts of interest to report regarding the present study.

\section{References}

1. Yusof, N. S. B., Sapuan, S. M., Sultan, M. T. H., Jawaid, M. (2020). Manufacturing process selection of green oil palm natural fiber reinforced polyurethane composites using hybrid TEA criteria requirement and AHP method for automotive crash box. Journal of Renewable Materials, 8(6), 647-660. DOI 10.32604/jrm.2020.08309.

2. Shaharuzaman, M. A., Sapuan, S. M., Mansor, M. R., Zuhri, M. Y. M. (2020). Conceptual design of natural fiber composites as a side-door impact beam using hybrid approach. Journal of Renewable Materials, 8(5), 549-563. DOI 10.32604/jrm.2020.08769.

3. Wuzella, G., Mahendran, A. R., Kandelbauer, A. (2020). Green composite material made from Typha latifolia fibres bonded with an epoxidized linseed oil/tall oil-based polyamide binder system. Journal of Renewable Materials, 8(5), 499-512. DOI 10.32604/jrm.2020.09615.

4. Célino, A., Fréour, S., Jacquemin, F., Casari, P. (2014). The hygroscopic behavior of plant fibers: A review. Frontiers in Chemistry, 1, 43. DOI 10.3389/fchem.2013.00043.

5. Cho, D., Kim, H. J., Drzal, L. T. (2013). Surface treatment and characterization of natural fibers: Effects on the properties of biocomposites. In: Polymer composites, pp. 133-177. Weinhein: Wiley-VCH.

6. Pickering, K. L., Li, Y., Farrell, R. L., Lay, M. (2020). Interfacial modification of hemp fiber reinforced composites using fungal and alkali treatment. Journal of Biobased Materials and Bioenergy, 1(1), 109-117. DOI 10.1166/ jbmb.2007.1984.

7. Li, X., Tabil, L. G., Panigrahi, S. (2007). Chemical treatments of natural fiber for use in natural fiber-reinforced composites: A review. Journal of Polymers and the Environment, 15(1), 25-33. DOI 10.1007/s10924-006-0042-3.

8. Mohanty, A. K., Misra, M., Drzal, L. T. (2001). Surface modifications of natural fibers and performance of the resulting biocomposites: An overview. Composite Interfaces, 8(5), 313-342. DOI 10.1163/156855401753255422.

9. Mohammed, L., Ansari, M. N. M., Pua, G., Jawaid, M., Islam, M. S. (2015). A review on natural fiber reinforced polymer composite and its applications. International Journal of Polymer Science, 2015(2), 1-15. DOI 10.1155/ 2015/243947.

10. Bledzki, A. K., Reihmane, J. G. (1996). Properties and modification methods for vegetable fibers for natural fiber composites. Journal of Applied Polymer Science, 59(8), 1329-1336. DOI 10.1002/(ISSN)1097-4628.

11. Saheb, D. N., Jog, J. P. (1999). Natural fiber polymer composites: A review. Advances in Polymer Technology, 18(4), 351-363. DOI 10.1002/(SICI)1098-2329(199924)18:4<351::AID-ADV6>3.0.CO;2-X. 
12. Li, Y., Mai, Y. W., Ye, L. (2000). Sisal fibre and its composites: A review of recent developments. Composite Science and Technology, 60(11), 2037-2055. DOI 10.1016/S0266-3538(00)00101-9.

13. Jacob, M., Joseph, S., Pothan, L. A., Thomas, S. (2005). A study of advances in characterization of interfaces and fiber surfaces in lignocellulosic fiber-reinforced composites. Composite Interfaces, 12(1-2), 95-124. DOI $10.1163 / 1568554053542115$.

14. Belgacem, M. N., Gandini, A. (2012). The surface modification of cellulose fibres for use as reinforcing elements in composite materials. Composite Interfaces, 12(1-2), 41-75. DOI 10.1163/1568554053542188.

15. Pothan, L. A., Luyt, A. S., Thomas, S. (2007). Polyolefin/natural fiber composites. In: Nwabunma, D., Kyu, T. (Eds.), Polyolefin composites, pp. 44-86. Hoboken: Wiley-Interscience.

16. Rong, M. Z., Zhang, M. Q., Liu, Y., Yang, G. C., Zeng, H. M. (2001). The effect of fiber treatment on the mechanical properties of unidirectional sisal-reinforced epoxy composites. Composite Science and Technology, 61(10), 1437-1447. DOI 10.1016/S0266-3538(01)00046-X.

17. Hill, C. A. S., Khalil, H. P. S. A., Hale, M. D. (1998). A study of the potential of acetylation to improve the properties of plant fibres. Industrial Crops and Products, 8(1), 53-63. DOI 10.1016/S0926-6690(97)10012-7.

18. Bledzki, A. K., Mamun, A. A., Lucka-Gabor, M., Gutowski, V. S. (2008). The effects of acetylation on properties of flax fibre and its polypropylene composites. Express Polymer Letters, 2(6), 413-422. DOI 10.3144/ expresspolymlett.2008.50.

19. Sreekala, M. S., Thomas, S. (2003). Effect of fibre surface modification on water-sorption characteristics of oil palm fibres. Composites Science and Technology, 63(6), 861-869. DOI 10.1016/S0266-3538(02)00270-1.

20. Joshy, M. K., Mathew, L., Joseph, R. (2009). Influence of fiber surface modification on the mechanical performance of isora-polyester composites. International Journal of Polymeric Materials and Polymeric Biomaterials, 58(1), 2-20. DOI 10.1080/00914030802461824.

21. Mahendran, A., Wuzella, G., Hardt-Stremayr, T., Gindl-Altmutter, W. (2016). Properties of woven natural fiberreinforced biocomposites. Journal of Renewable Materials, 4(3), 215-224. DOI 10.7569/JRM.2016.634110.

22. Valadez-Gonzalez, A., Cervantes-Uc, J. M., Olayo, R., Herrera-Franco, P. J. (1999). Effect of fiber surface treatment on the fiber-matrix bond strength of natural fiber reinforced composites. Composite Part B: Engineering, 30(3), 309-320. DOI 10.1016/S1359-8368(98)00054-7.

23. Mishra, S., Misra, M., Tripathy, S. S., Nayak, S. K., Mohanty, A. K. (2001). Potentiality of pineapple leaf fibre as reinforcement in PALF-polyester composite: Surface modification and mechanical performance. Journal of Reinforced Composites, 20(4), 321-334. DOI 10.1177/073168401772678779.

24. Hill, C. A. S., Abdul Khalil, H. P. S. (2000). Effect of fiber treatments on mechanical properties of coir or oil palm fiber reinforced polyester composites. Applied Polymer Science, 78(9), 1685-1697. DOI 10.1002/(ISSN)1097-4628. 